\title{
Successful Surgical Management of Foreign Body in Tortoise
}

\author{
A.T. Yamgar, D.U. Lokhande, G.U. Yadav* and P.S. Dakhne \\ Department of Veterinary Surgery and Radiology, Bombay Veterinary College, \\ Parel, Mumbai-12, India \\ *Corresponding author
}

\section{A B S T R A C T}

\section{Keywords}

Tortoise, foreign body, Celiotomy, Plastrotomy

Article Info

Accepted:

10 January 2019

Available Online:

10 February 2019
Two cases of tortoise presented to the outpatient department of Surgery \& Radiology, Bombay Veterinary College, Parel, Mumbai with complaint of anorexia and vomition, lethargy, reluctance to walk and slightly reddish ocular mucous membranes since long time. The clinical approach included history, clinical examination, radiography, surgical management along with supportive medication. On radiographical examination, there was some radio opaque material in stomach. On surgical excision, there was rusted iron wire in one case and ear ornaments in another case. The celiotomy by plastrotomy for removal of foreign bodies in both tortoises proved to be a viable, very important and safe technique to the survival of chelonians. Both foreign bodies were successfully removed surgically. Celiotomy incision was closed in routine manner. Shell was sutured by using adhesive tape for next 10 day of post-operative period. Adhesive tape of shell was removed on $15^{\text {th }}$ post operative day.

\section{Introduction}

The poor nutrition and lack of regular cleaning of the area which the animal lives possibly has been the major cause for the ingestion of foreign bodies by chelonian. Tortoises, terrestrial chelonians highly sought after as pets are prone to infectious and parasitic diseases outbreaks in captivity due to environmental and hygienic conditions (Rosskopf and Shindo, 2003).

They are usually omnivores in the wild eating leaves, flowers, fruits, grass, invertebrates, carcasses and other foods they may find on the ground (Baptistotte and Cubas, 2006).
Geophagy is a common habit for many chelonian species, which results in the ingestion of foreign bodies, lodged in the substrate (Matushima, 2001). Those bodies may obstruct the gastrointestinal tract and lead them to death, or even damage the gastroenteric walls, reduce nutritional gain and increase intestinal transit (Bjorndal 1997, Oliveira et al., 2009).

Tortoises, turtles and terrapins are vertebrates with similar organ systems to mammals. However, they are ectothermic and rely on environmental temperature and behavior to control their core body temperature. They possess both renal and hepatic portal 
circulations, and predominantly excrete ammonia, urea, or uric acid depending upon their evolutionary adaptations. Tortoises are characterized by a hard shell, formed dorsally by the carapace and ventrally by the plastron. The shell is composed of bony plates overlaid by offset keratin scutes, and each area has a specific name. Tortoises possess a common cloaca which receives the lower gastrointestinal, reproductive, and urinary tracts (Stephen, 2015).

\section{Case 1}

1 year old tortoise was presented with complaint of anorexia, vomition, lethargy, reluctance to walk. On clinical examination, there was slightly reddish ocular mucous membranes, dull, dehydrated and emaciated since long time. On basis of clinical examination, it was treated medicinally for 5 days but even after medicinal treatment, there was no improvement in condition. On radiological examination, there was some radio opaque ear ornaments in stomach. On the basis of radiological examination, it was decided to a case foreign body in stomach and plan for surgical removal of foreign body according to body condition of tortoise (Fig. $1)$.

\section{Case 2}

2.5 year old tortoise was presented to outpatient department of veterinary surgery and radiology, Bombay Veterinary College, Parel with complaint of anorexia, vomition. On full anamnesis, owner said that something was chewed before 15 days. On clinical examination, there were slightly reddish ocular mucous membranes, dull, lethargic. On basis of clinical examination, it was treated medicinally for 2 days by local veterinarian but after 2 days, there was persistence of condition and start deteriorating changes thats why local veterinarian transferred to us. On radiological examination, there was some long bended radio opaque substance in stomach. On the basis of radiological examination, it was decided to a case foreign body in stomach and plan for surgical removal of foreign body according to body condition of tortoise (Fig. 2).

\section{Surgical treatment}

The opening of the plastron was performed through the abdominal shields by a circular mini grinding saw for home use. The incision was rectangular with a $45^{\circ}$ inclination. It was irrigated with saline during the plastron osteotomy. The fragment was raised by means of a periosteal elevator, separated from the muscle under the plastron and preserved in ringer lactate solution until its reimplantation. A midline incision was performed between the two abdominal veins to access the abdominal cavity. After the location of the stomach, the gastrotomy was held for the extraction of foreign bodies. Soon after, one preceded the gastroraphy, performed in seromuscular pattern in two plans of suture, the first one simple separated and the following in continuous inverse pattern, both with 3-0 polyglactin 910 . The suture of the coelomic membrane was simple separated, with 3-0 polyglactin 910 , and the fragment of the plastron was restored to its original position. After cleaning and degreasing the operative field with ether, one applied autopolymerizing acrylic resin for the protection and immobilization of the fragment. The surgical procedure was successful, which was confirmed by the radiographic evaluation in the immediate postoperative period. The postoperative medication protocol consisted of meloxicam (0.1 mg / kg, IM, SID/3days, Maxicam, Ourofino, Brazil), doxycycline (10 mg / kg, IM, SID/6 days, doxiciclina, Vetnil, Brazil) and dietary treatment (leaves, fruits and eggs crushed in blender) supplied with the aid of a 
syringe. The animal was discharged 10 days after surgery. At the last evaluation three months postoperatively, the animal was in excellent health.

\section{Results and Discussion}

The poor nutrition and lack of regular cleaning of the area which the animal lives possibly has been the major cause for the ingestion of foreign bodies by chelonian. A study with sea turtles observed that $100 \%(\mathrm{n}=$ 29 ) of the animals were contaminated with solid waste, which suggests that the amplitude of variation in the amount of foreign bodies found is directly related to their availability in the environment and/or the absence of food (Tourinho et al., 2008). In most cases foreign bodies in the gastrointestinal tract of chelonians often occur in the stomach. Those bodies usually suffer fragmentation; increasing sub-lethal effects due to the increasing of the contact surface of the items with the gastrointestinal walls, resulting in a diminished capacity on nutrient uptake (Tourinho et al., 2008). The present case report confirmed all the above-cited observations, including pallor and apathy, which revealed malnutrition. The clinical signs and the confirmation of the diagnosis by dorsi-ventral radiographic were enough to confirm the presence of foreign bodies, such as observed in a green turtle (Chelonia mydas) with intestinal obstruction (Helmick et al., 2000). The literature diverges on the approach of gastrointestinal foreign bodies in turtles. Some authors suggest a conservative approach (natural elimination of foreign bodies), which was successful in sea-turtles (Mas 2001, Tourinho et al., 2008) and was therefore adopted in this case report.

However, surgery was necessary once the first procedure was unsuccessful. Thus, the recommendation proposed by the literature is that surgical intervention must be immediately performed after the diagnosis of foreign body (Raphael, 2003). Furthermore, the animal presented signs of toxemia, like apathy, reluctance to walk, and slightly reddish ocular mucous membranes, making surgery the most important option for the survival of the patient. Regarding the anesthetic protocol in chelonians isoflurane is considered the most appropriate anesthetic, although a dissociative anesthetic such as ketamine may be used alone or combined with tranquilizers and analgesics (Baptistotte and Cubas, 2006). The protocol adopted in this case was sufficient to keep the turtle in anesthetic plan, allowing a safe surgery (Fig. $3)$.

Fig.1\&2 X-Ray of case no 1 showing ear Ornaments in stomach of tortoise and X-Ray of case no 2 showing linear foreign body meal wire in stomach of tortoise
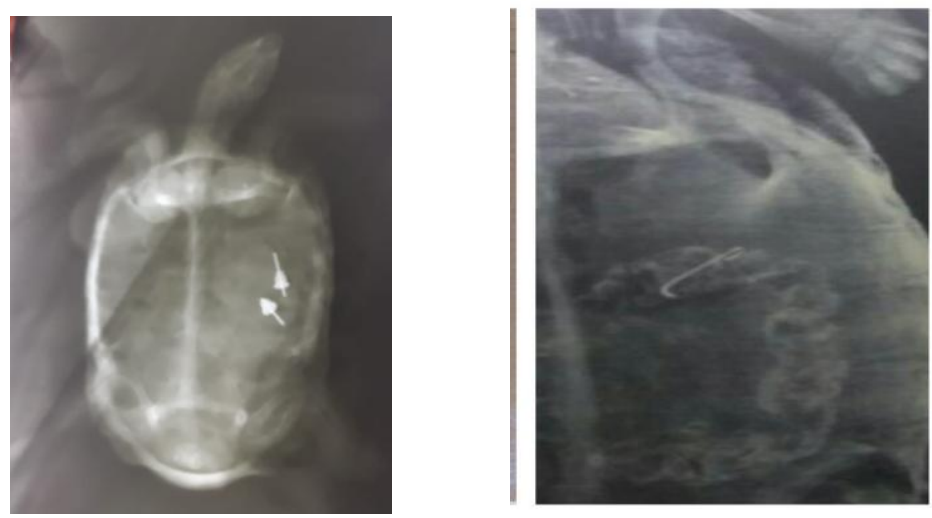
Fig.3 Operative procedure for removal of foreign body i.e. ear ornaments in case no. 1
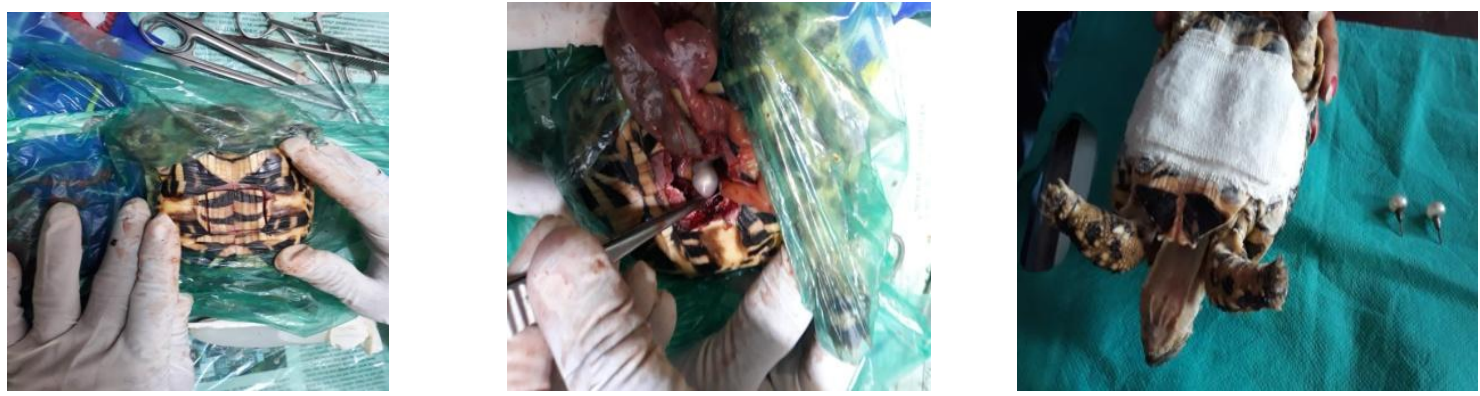

Fig.4 Operative procedure for removal of foreign body i.e. mealic wire in case no 2
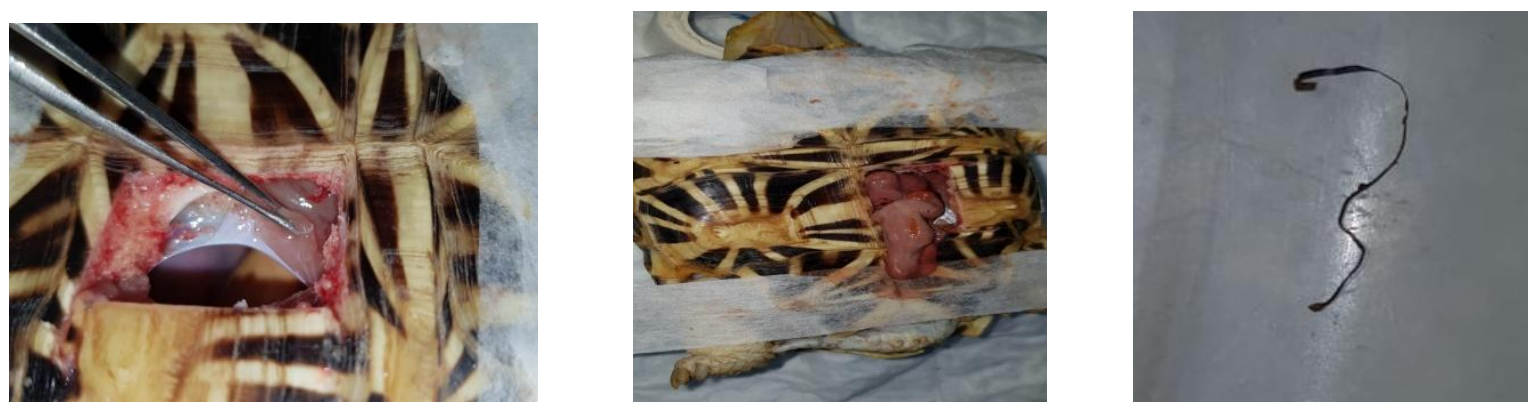

The coelomic cavity in chelonians may be accessed by celiotomy after the opening of the plastron, which was successfully used for removal of foreign bodies in a case of intestinal compactation in a D'Orbigny's slider turtle (Trachemys dorbignyi) (Oliveira et al., 2009) or by the prefemoral fossae, which was successful in performing laparoscopic oophorectomy in a red eared slider turtle (Trachemys scripta elegans) (Pessoa et al., 2008). In the case herein reported one decided on the celiotomy with plastron opening due to the lack of laparoscopy equipment at the hospital where the animal was taken to. Besides, the technique provides a better evaluation of the coelomic cavity (Miwa, 2010). Although an invasive procedure with slow healing and rehabilitation (Oliveira et al., 2009), the option was efficient for the animal. The oblique incision in the plastron was considered important because it prevented the fragment which was removed to dislocate and broke into the cavity after replacement
(Baptistotte and Cubas, 2006) (Fig. 4). The procedure probably contributed to the satisfactory postoperative recovery observed in the tortoise. The autopolymerizing acrylic resin for the protection and immobilization of the fragment of the plastron is supported by the literature (Pachaly, 1992) and presented good results, allowing the patient an excellent postoperative recovery. One proved that the celiotomy by plastrotomy for the removal of gastrointestinal foreign bodies was a viable and safe technique for the survival of the chelonian.

\section{References}

Baptistotte C. and Cubas P.H. (2006) Chelonia (Tartaruga, Cágado, Jabuti). In: Cubas Z.S.J., Silva C.R. and CatãoDias J.L. (Eds), Tratado de Animais Selvagens. Roca, São Paulo p.86-119

Bjorndal K.A. (1997) Foraging ecology and nutrition of sea turtles. In: Lutz P.L. and Musick J.A. (Eds), The Biology of Sea 
Turtles. CRC Press, Florida. Pp. 199231

Helmick K.E., Bennett R.A., Ginn P., Dimarco N., Beaver D.P. and Dennis P.M. (2000) Intestinal volvulus and stricture associated with a leiomyoma in a green turtle (Chelonia mydas). J. Zoo Wildl. Med. 31:221-227

Mas M. (2001) Chelonian noninfectious diseases. In: Fowler M.E. and Cubas Z.S. (Eds), Biology, Medicine and Surgery of South America Wild Animals. Iowa State University Press, Ames., Pp. 25-27.

Matushima E.R. (2001). Chelonian infectious diseases and general medicine, p.22-24. In: Fowler M.E. and Cubas Z.S. (Eds), Biology, Medicine and Surgery of South America Wild Animals. Iowa State University Press, Ames

Miwa Y. (2010). Removal of urinary calculi via the cloaca in tortoises. Exotic 10:5-7

Oliveira F.S., Delfini A., Martins L.L., Faria $\mathrm{Jr}$ D. and Machado M.R.F. (2009). Obstrução intestinal em tigre d'água (Trachemys dorbignyi). Acta Scientiae Veterinariae, 37: 307-310.
Pachaly J.R. 1992. Doenças nutricionais das aves silvestres cativas, p.80- 81. In: Ibid. (Ed.), Medicina de Animais Selvagens, Apostila, Curitiba

Pessoa C.A., Rodrigues M.A., Kozu F.O., Prazeres R.F. and Fecchio R.S. (2008). Ooforectomia videoassistida por acesso pré-femural em tartaruga-de-ouvidovermelho (Trachemys scripta elegans). Pesq. Vet. Bras. 28: 345-349.

Raphael B.L. (2003) Chelonians (turtles, tortoises), p.48-58. In: Fowler M.E. and Miller R.E. (Eds), Zoo and Wild Animal Medicine. 5th ed. Saunders Elsevier, St Louis., Missouri.

Stephen J Divers (2015) Clinical Approach to Tortoises and Turtles, Exotics Con Main Conference Proceedings, Pp. 541-551.

Tourinho P.S., Ivar do Sul J.A. and Fillmann G. (2008) Freqüência de ingestão e tipos de resíduos sólidos em tartarugasverdes na costa do Rio Grande do Sul, Brasil: distribuição e fragmentação no trato gastrointestinal. III Congresso Brasileiro de Oceanografia CBO'2008, I Congresso IberoAmericano de Oceanografia - I CIAO, Fortaleza, CE.

\section{How to cite this article:}

Yamgar, A.T., D.U. Lokhande, G.U. Yadav and Dakhne, P.S. 2019. Successful Surgical Management of Foreign Body in Tortoise. Int.J.Curr.Microbiol.App.Sci. 8(02): 922-926. doi: https://doi.org/10.20546/ijcmas.2019.802.105 